\title{
The basolateral amygdala is a cofactor in memory enhancement produced by intrahippocampal glutamate injections
}

\author{
MARK G. PACKARD and SCOTT A. CHEN \\ University of New Orleans, New Orleans, Louisiana
}

\begin{abstract}
In the present experiments, the modulatory influence of the basolateral amygdala on hippocampaldependent memory processes was examined. Adult male Long-Evans rats were trained in a daily session in a win-shift radial maze task to obtain food from four randomly selected maze arms. After a delay period, they were returned to the maze with all the arms accessible and allowed to obtain four pellets from those arms that were not previously visited. Following criterion training with 5-and 15-min delay periods, the rats were given a drug test in which they received a posttraining intracerebral drug treatment immediately following the first four food-rewarded choices. In Experiment 1, the treatment consisted of an intrahippocampal or intra-amygdala injection $(0.5 \mu \mathrm{l})$ of either a $2 \%$ solution of the local anesthetic lidocaine or saline. Four hours after injection, the rats were returned to the maze for a retention test. Posttraining intrahippocampal, but not intra-amygdala, injections of lidocaine impaired retention test choice accuracy. In Experiment 2, the rats unilaterally cannulated in two brain regions (the hippocampus and the basolateral amygdala) received posttraining intrahippocampal injections of glutamate or saline and concurrent intra-amygdala injections of lidocaine or saline. Intrahippocampal injection of glutamate $(2.0 \mu \mathrm{g} / 0.5 \mu \mathrm{l})$ enhanced memory in the win-shift task when an 18-h delay was used. Concurrent posttraining intra-amygdala injections of lidocaine blocked the memory-enhancing effects of intrahippocampal glutamate administration. The findings suggest that, although a functional basolateral amygdala is not essential for normal memory in a hippocampal-dependent win-shift radial maze task, the basolateral amygdala is a necessary cofactor in the memory-enhancing effects of posttraining intrahippocampal injections of glutamate.
\end{abstract}

According to the modulatory view of the role of the amygdala in memory, posttraining manipulation of this structure influences memory processes occurring in brain regions receiving efferent amygdala projections (for reviews, see McGaugh, Cahill, \& Roozendaal, 1996; Packard, Williams, Cahill, \& McGaugh, 1995). This hypothesis was originally derived from evidence indicating that lesions of the stria terminalis attenuate the memoryenhancing and memory-impairing effects of a wide range of posttraining drug and hormone treatments, without affecting memory in otherwise untreated rats (see, e.g., Introini-Collison, Arai, \& McGaugh, 1989; IntroiniCollison, Miyasaki, \& McGaugh, 1991; Liang \& McGaugh, 1983; McGaugh, Introini-Collison, Juler, \& Izquierdo, 1986).

We have recently begun to examine candidate brain regions that may receive a memory modulatory influence from the amygdala (Packard, Cahill, \& McGaugh, 1994; Packard \& Teather, 1998). The hippocampus is a brain structure with a well-established involvement in memory

This research was supported by NIMH Grant R2956973-01 to M.G.P. The authors thank Jeff Wingard for surgical and histological assistance. Correspondence concerning this article should be addressed to M. G. Packard, Department of Psychology, Yale University, 2 Hillhouse Avenue, New Haven, CT 06520-8205 (e-mail: mark.packard@ yale.edu). (for a review, see Squire, Knowlton, \& Musen, 1993), and anatomical data indicate that the rat hippocampal system receives extensive projections from basolateral and lateral amygdala nuclei (e.g., Finch et al., 1986; Krettek \& Price, 1977, 1978). A neural connection between the amygdala and the hippocampus is also suggested by findings indicating that electrical stimulation of the basolateral amygdala evokes field potentials in the dentate gyrus (Ikegaya, Saito, \& Abe, 1996), whereas injection of $N$-methyl-Daspartate into the basolateral nucleus induces $c$-fos expression in the dentate (Cahill \& McGaugh, 1993).

Few studies have examined the functional significance of amygdalo-hippocampal projections; however, recent findings from electrophysiologcial and behavioral experiments are consistent with the hypothesis that efferent amygdala projections may modulate hippocampaldependent memory processes. For example, lesions of the basolateral nucleus attenuate hippocampal long-term potentiation induced in the dentate gyrus (Ikegaya, Saito, \& Abe, 1994, 1995), a putative physiological mechanism of hippocampal memory processes (Bliss \& Collinridge, 1993). In addition, although pretraining lesions of the amygdala do not impair acquisition of a hippocampaldependent hidden platform water maze task (Sutherland \& McDonald, 1990), posttraining intra-amygdala injections of amphetamine produce a robust enhancement of memory in this task (Packard et al., 1994; Packard \& 
Teather, 1998). Preretention test intra-amygdala injections of the local anesthetic lidocaine do not block expression of the memory-enhancing effect of posttraining intraamygdala amphetamine (Packard et al., 1994; Packard \& Teather, 1998), suggesting that the memory-enhancing effects of intra-amygdala amphetamine injections are not mediated by storage of memory within the amygdala. In contrast, the memory-enhancing effects of intra-amygdala amphetamine injections are blocked by concurrent posttraining injections of lidocaine into the hippocampus (Packard \& Teather, 1998), indicating that the hippocampal system receives a memory modulatory influence via efferent amygdala projections.

The present experiments were designed to address two further questions concerning amygdala modulation of hippocampal-dependent memory processes. First, previous findings using pretraining irreversible lesion techniques indicate that a functional amygdala is not necessary for the acquisition of hippocampal-dependent tasks, including a hidden platform water maze task (Sutherland \& McDonald, 1990) and win-shift behavior in a radial maze (Becker, Walker, \& Olton, 1980; Kesner, 1992; McDonald \& White, 1993). However, the lack of an effect of pretraining amygdala lesions on acquisition of these tasks may reflect a compensatory response or recovery of function following lesions, and a functional amygdala during training still may confer some advantage in a hippocampal-dependent task. One way of examining this question is to assess the effects of a posttraining reversible amygdala lesion (e.g., via injection of lidocaine) on memory in a hippocampal-dependent task. Therefore, Experiment 1 examined the effects of posttraining intraamygdala and intrahippocampal injections of lidocaine on memory in a win-shift radial maze task.

A second question is whether a functional amygdala is a necessary cofactor in the effects of a posttraining intrahippocampal treatment on memory. Recent findings are consistent with this hypothesis; pretraining neurotoxic lesions of the basolateral amygdala blocked the memoryenhancing effects of posttraining intrahippocampal injection of a glucocorticoid receptor agonist in an inhibitory avoidance task (Roozendaal \& McGaugh, 1997). In Experiment 2 , we addressed the issue of whether the basolateral amygdala is a cofactor in the memory-enhancing effects of an intrahippocampal treatment, using posttraining manipulations of both structures. Rats cannulated in the basolateral amygdala and the hippocampus received a posttraining intrahippocampal injection of the neurotransmitter glutamate and a concurrent intra-amygdala injection of lidocaine.

\section{EXPERIMENT 1 Effect of Posttraining Intra-Amygdala and Intrahippocampal Lidocaine on Memory in a Win-Shift Radial Maze Task}

\section{Method}

Subjects. The subjects were 35 male Long-Evans rats (275-300 g) individually housed in a temperature-controlled environment on a 12:12-h light:dark cycle (lights on, 7 a.m. -7 p.m.). The animals were given ad-lib access to water.

Apparatus. The apparatus was an elevated $(60-\mathrm{cm})$ black Plexiglas eight-arm radial maze. Each maze arm measured $60 \times 9 \mathrm{~cm}$, and the diameter of the center platform was $40 \mathrm{~cm}$. Food cups were drilled into the floor at the end of each arm. The maze was located in a testing room containing several extramaze cues.

Drugs and injection procedures. A $2 \%$ lidocaine hydrochloride solution was used (Abbott Laboratories). Bilateral injections of lidocaine or saline $(0.5 \mu \mathrm{l} / \mathrm{side})$ were administered intracerebrally via guide cannula, using 30 -gauge injection needles connected by polyethylene tubing to $10-\mu \mathrm{l}$ hamilton microsyringes. The injections were delivered over $37 \mathrm{sec}$, using an electronic syringe pump, and the injection needles (extending $1 \mathrm{~mm}$ from the end of the guide cannula) were left in place an additional $60 \mathrm{sec}$ to allow for diffusion of solution away from the needle tip.

Surgery. Prior to surgery, the rats were anesthetized with $50 \mathrm{mg} / \mathrm{kg}$ of sodium pentobarbital. In Experiment 1, in which the potential impairing effects of lidocaine on memory were examined, bilateral guide cannulas ( 23 gauge) were implanted, using standard stereotaxic techniques. The guide cannula were attached to the skull with jeweler screws and dental cement. For the dorsal hippocampal placements, coordinates for the guide cannula were $\mathrm{AP}=-3.1 \mathrm{~mm}$, $\mathrm{ML}= \pm 1.5 \mathrm{~mm}$ from bregma, and $\mathrm{DV}=-3 \mathrm{~mm}$ from the skull surface (atlas of Paxinos \& Watson, 1997). Coordinates for the basolateral placements were $\mathrm{AP}=-2.2 \mathrm{~mm}, \mathrm{ML}= \pm 4.7 \mathrm{~mm}$ from bregma, and DV $=-7 \mathrm{~mm}$ from the skull surface. These coordinates were chosen on the basis of our previous findings with posttraining intrahippocampal and intra-amygdala drug treatments (Packard \& Teather, 1998). After surgery, stylets were inserted into the guide cannula and left in place until the injections, in order to ensure cannula patency. Behavioral procedures began 10 days after surgery.

Histology. After behavioral testing, the rats were deeply anesthetized with a $1-\mathrm{cc}$ injection of sodium pentobarbital $(50 \mathrm{mg} / \mathrm{cc})$ and perfused with a $10 \%$ formal-saline solution. The brains were removed and fixed in a $10 \%$ formal-saline solution before slicing Frozen sections were cut at $20 \mu \mathrm{m}$ through the cannula tract area, and cresyl-violet-stained sections were mounted and examined for verification of cannula placements, using the atlas of Paxinos and Watson (1997). Histological results are shown in Figure 1. Dorsal hippocampal placements ranged from -2.80 to $-3.60 \mathrm{~mm} \mathrm{AP}$ from bregma, and placements in the basolateral amygdala ranged from -1.80 to $-2.56 \mathrm{~mm}$ AP from bregma (Figure 1).

Behavioral procedures. The behavioral procedures used were similar to those previously described (Packard \& White, 1989, 1991) and were adapted from early studies using the delayed win-shift radial maze task (Beatty \& Shavalia, 1980; Maki, Betty, Hoffman, Bierly, \& Clouse, 1984). Before training, the rats were reduced to $85 \%$ of their ad-lib feeding weights. Each rat was individually placed on the maze for $5 \mathrm{~min}$ on 2 consecutive days and allowed to explore the maze with no food available. On both maze habituation days, the rats were allowed to consume ten 45-mg Noyes Formula $A$ food pellets in their home cages. Food trials began on Day 3. On each food trial, four randomly selected maze arms were blocked with removable Plexiglas shields, and the other four arms were baited with a single Noyes food pellet. The rats were allowed to obtain food from the four open arms. If a rat did not retrieve all four pellets within $5 \mathrm{~min}$, it was removed from the maze and returned to its home cage until the next day's trial. A delay period (specified below) followed the first four food-rewarded choices, and then the rats were returned to the maze for a retention test. During the retention test, all eight maze arms were open, and only those arms that had been blocked before the delay contained food. The rats were removed from the maze after the four baited arms had been chosen. Records were kept of the arms entered and the order of entry. Visits to unbaited arms on the retention test were scored as errors. 

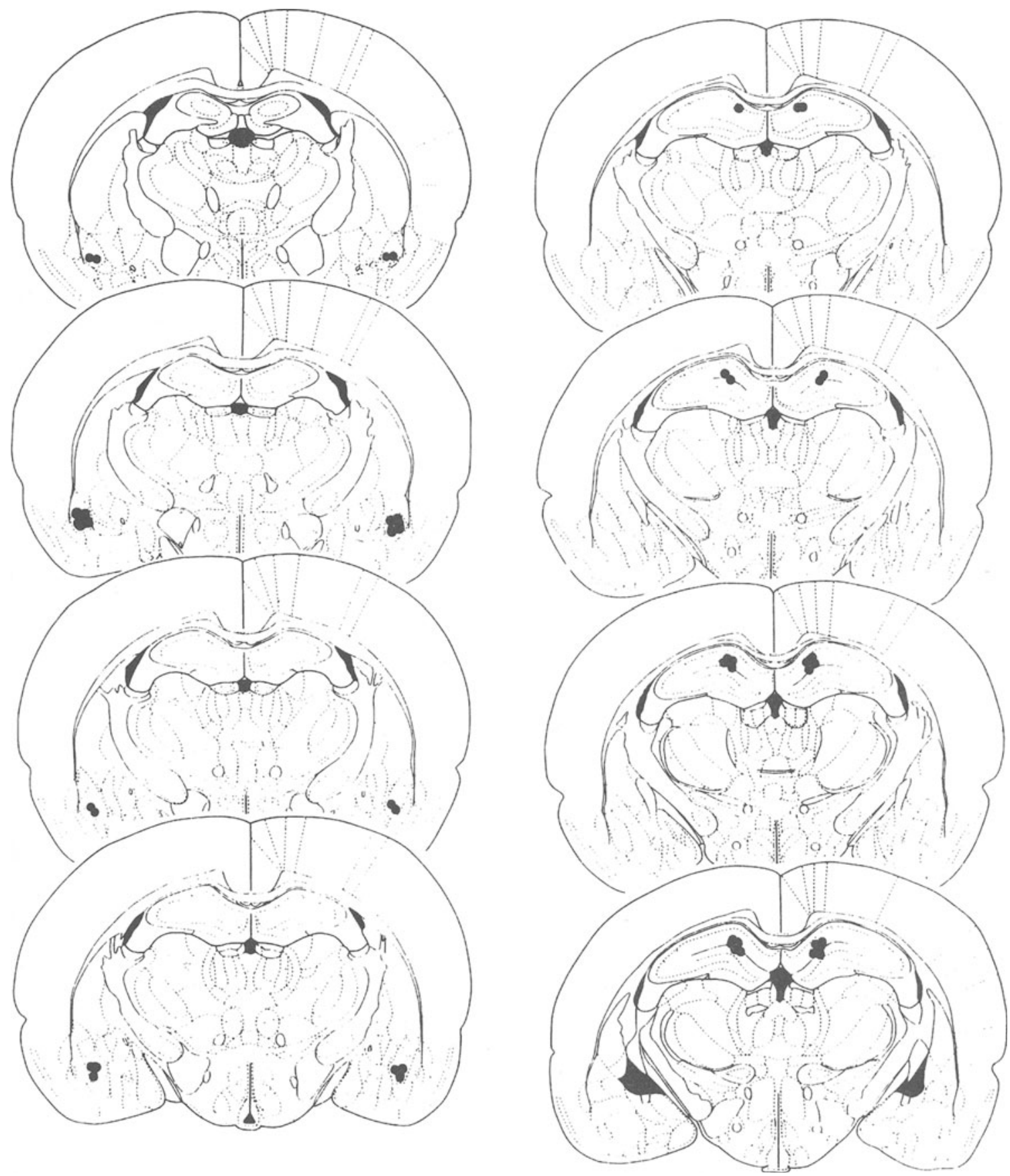

Figure 1. Injection needle tip locations (with overlap) for the bilateral basolateral amygdala placements (left) and the dorsal hippocampal placements (right). Basolateral amygdala: top, $-1.80 \mathrm{~mm}$; upper middle, $-2.12 \mathrm{~mm}$; lower middle, $-2.30 \mathrm{~mm}$; bottom, $-2.56 \mathrm{~mm}$ from bregma. Dorsal hippocampus: top, $-2.80 \mathrm{~mm}$; upper middle, $-3.14 \mathrm{~mm}$; lower middle, $-3.30 \mathrm{~mm}$; bottom, $-3.60 \mathrm{~mm}$ from bregma (atlas of Paxinos \& Watson, 1997).

There were two training phases followed by a test (i.e., drug) trial. For each of the training phases, a criterion was established that required at least four correct responses in the first five retention test choices (i.e., $80 \%$ correct) on 2 consecutive days. Animals passed out of a phase by meeting this criterion. The delay in the first phase was $5 \mathrm{~min}$; the delay in the second phase was $15 \mathrm{~min}$. Once an animal had reached criterion at the 15-min delay, the test (i.e., drug) trial was given on the following day. On this trial, the rats were removed from the maze after the four predelay choices and received an intrahippocampal or intra-amygdala injection of either lidocaine or saline ( $N=8-9$ rats/group). The retention test was given after a delay of $4 \mathrm{~h}$. In previous studies using these training parameters, the performance of control rats deteriorated as the test trial delay was extended from 4 to $18 \mathrm{~h}$ (Packard \& White, 1989). At the 4-h 


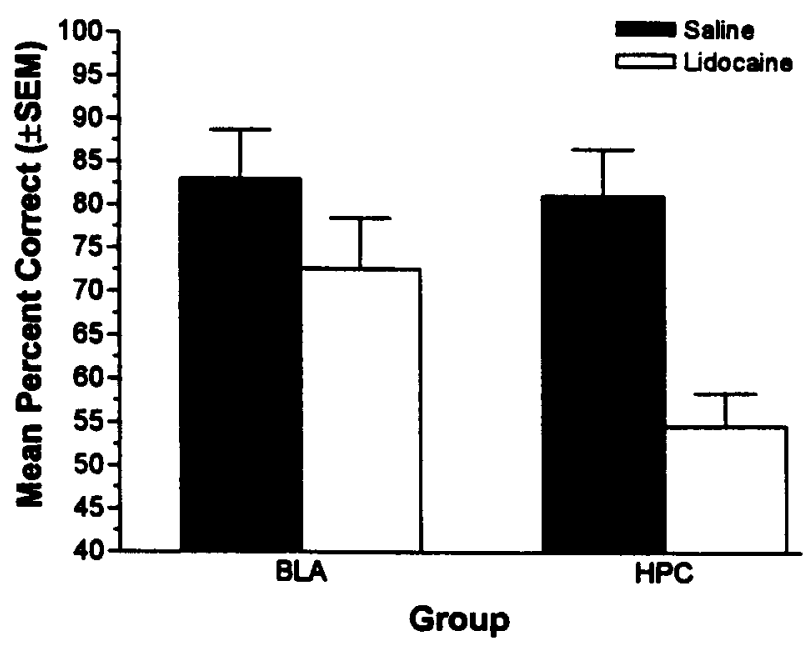

Figure 2. Effects of posttraining intrahippocampal and intrabasolateral amygdala injections of lidocaine on memory in a win-shift radial maze task. BLA, basolateral amygdala; HPC, hippocampus; $S E M$, standard error of the mean.

delay used, the performance of control rats was approximately $80 \%$ correct on the retention test trial (Packard \& White, 1989). Thus, a 4-h delay allows for the assessment of potential memory-impairing effects of intracerebral lidocaine injections. The rats were assigned to treatment groups, using a rank-order method as each reached the 15-min criterion. The use of a rank-order method in assigning animals to treatment groups ensures that the mean number of trials to criterion (i.e., through the 5- and 15-min delay periods) is similar across groups.

\section{Results}

The mean number of trials to criterion for each group were as follows: basolateral amygdala-saline, 15.4 trials, 1.24 standard error of the mean (SEM); basolateral amygdala-lidocaine, 17.0 trials, $0.83 S E M$; hippocampussaline, 17.0 trials, 1.49 SEM; and hippocampus-lidocaine, 15.44 trials, 1.23 SEM. A one-way analysis of variance (ANOVA) computed on the number of trials to criterion revealed no significant group differences $[F(3,31)=0.56$, n.s.]. The lack of group differences in the number of trials to criterion indicates that any effects produced by the posttraining treatments on the test day are not due to differential rates of task acquisition among groups.

The effect of posttraining intrahippocampal and intraamygdala injections of lidocaine on memory in the winshift radial maze task is shown in Figure 2. A one-way ANOVA computed on the number of errors made on the retention test revealed a significant group effect $[F(3,31)=$ $6.17, p<.01]$. Scheffé's post hoc tests revealed that rats receiving intrahippocampal injections of lidocaine made significantly more errors than did saline-treated rats $(F=$ $4.41, p<.01$ ), indicating that intrahippocampal lidocaine injections produced an impairment of memory. In contrast, there was no significant difference in the number of errors made on the retention test by rats receiving intra-amygdala injections of lidocaine, relative to salinetreated animals $(F=0.63$, n.s.), indicating that intraamygdala lidocaine injections had no effect on memory.

\section{Discussion}

Posttraining intrahippocampal injections of the local anesthetic lidocaine impaired memory in a win-shift radial maze task, whereas similar injections into the basolateral amygdala had no effect on memory. The volume of solution injected in this study $(0.5 \mu 1)$ is typical of that of numerous studies examining the effects of intracerebral drug treatments on behavior. However, in the absence of autoradiographic analyses, it should be noted that the possibility of the injection spreading to other brain areas cannot be completely ruled out. Nonetheless, the likelihood that the injections acted at their intended target to produce behavioral effects in the present study is consistent with converging evidence from studies that have employed pretraining irreversible lesion techniques: Hippocampal system lesions severely impair acquisition of this task, whereas large amygdala lesions have no effect (Becker et al., 1980; Kesner, 1992). The lack of an effect of pretraining amygdala lesions observed previously in hippocampal-dependent spatial memory tasks is not due to a compensatory response or recovery of function following surgery, since, in the present study, disruption of a functional amygdala during the posttraining period similarly did not affect task performance. In addition, the lack of an effect of intra-amygdala lidocaine injections $(2 \% ; 0.5 \mu \mathrm{l})$ on memory in the win-shift radial maze task is not due to the use of an inappropriately low dose of solution, since posttraining intrabasolateral amygdala injections of lidocaine in a considerably lower volume $(2 \%$; $0.25 \mu \mathrm{l})$ can impair memory in an inhibitory avoidance task (Parent \& McGaugh, 1994).

Our previous findings indicate that posttraining intraamygdala injections of amphetamine enhance memory in a hippocampal-dependent hidden platform water maze task (Packard et al., 1994; Packard \& Teather, 1998). However, posttraining intra-amygdala injections of lidocaine had no effect on memory in a win-shift radial maze task (present study) or in a hidden platform water maze task (Packard \& Chen, unpublished data). In addition, intra-amygdala injection of scopolamine (McIntyre, Ragozzino, \& Gold, 1998) and morphine (Ragozzino \& Gold, 1994) impaired memory in amygdaladependent conditioned place preference and inhibitory avoidance tasks, respectively, while having no influence on hippocampal-dependent spatial tasks. These findings suggest that a functional amygdala during training does not confer a mnemonic advantage in a hippocampaldependent task. Thus, the memory modulatory influence of the amygdala on the hippocampal system may be unidirectional for valence, acting solely to facilitate hippocampaldependent memory (see, e.g., Packard et al., 1994; Packard \& Teather, I998). 


\section{EXPERIMENT TWO Amygdala Modulation of the Memory-Enhancing Effects of Intrahippocampal Glutamate Injection}

In Experiment 2, we investigated the possibility that amygdala function is a necessary cofactor in the memoryenhancing effect of a posttraining intrahippocampal injection of glutamate. Glutamate was examined, in part, because it is the principal neurotransmitter in corticohippocampal projections (for a review, see Otterson, Osen, \& Laake, 1995) and is presumed to provide the hippocampal system with sensory information used for mnemonic processing. In addition, recent behavioral evidence indicates that posttraining intrahippocampal injections of glutamate enhance memory (Izqueirdo et al. 1992; Packard \& Teather, 1999). In order to examine the hypothesis that the amygdala is a cofactor in the memory-enhancing effects of intrahippocampal injections of glutamate, rats cannulated in both the hippocampus and the basolateral amygdala received a posttraining intrahippocampal injection of glutamate or saline and a concurrent intra-amygdala injection of lidocaine or saline. If the memory-enhancing effects of intrahippocampal glutamate injections require a modulatory influence via the amygdala, intra-amygdala lidocaine injections should block such enhancement.

\section{Method}

Subjects. The subjects were 19 male Long-Evans rats (275$300 \mathrm{~g}$ ), housed in conditions identical to those of Experiment 1.

Apparatus. The radial maze was the same as that used in Experiment 1 .

Drugs and injection procedures. Glutamate (L-glutamic acid; Research Biochemicals International) was dissolved in physiological saline. A 2\% lidocaine hydrochloride solution (Abbott Laboratories) was used. The parameters for the unilateral intracerebral injections were identical to those of Experiment 1. Glutamate was injected at a dose of $2.0 \mu \mathrm{g}$, and this dose was selected on the basis of our previous findings with posttraining intrahippocampal injections of glutamate in a hidden platform water maze task (Packard \& Teather, 1999). The volume for all injections was $0.5 \mu \mathrm{l}$.

Surgery. In Experiment 2, the potential memory-enhancing effects of posttraining intrahippocampal glutamate infusions and the mediation of this effect by basolateral amygdala function were examined. Therefore, the rats received unilateral (left-side) cannula implantation in both brain structures, using the same surgical procedures and brain coordinates as those used in Experiment 1 and in our previous study of amygdala modulation of hippocampal memory processes (Packard \& Teather, 1998). Unilateral implantations were done, in part, to preclude the cannula-induced brain damage that may accompany bilateral (i.e., four guide cannulas) implantation in both structures. In addition, amygdala-hippocampal projections in the rat are predominantly ipsilateral in nature (Petrovich, Canteras, \& Swanson, 1997), and posttraining unilateral intrahippocampal and intra-amygdala drug injections effectively enhance memory (see, e.g., Packard et al., 1994; Packard \& Teather, 1998).

Histology. The histological procedures were identical to those of Experiment 1 and the results are shown in Figure 3. Dorsal hippocampal placements ranged from -2.80 to $-3.60 \mathrm{~mm}$ AP from bregma, and placements in the basolateral amygdala ranged from -1.80 to $-2.56 \mathrm{~mm}$ AP from bregma (Figure 3 ).

Behavioral procedures. The behavioral training procedures were similar to those of Experiment 1 (i.e., win-shift radial maze training until criterion was met at both the 5- and the 15-min delay periods). However, instead of a 4-h delay period on the test day, an 18-h delay was used. At the 18-h delay, the performance of control rats is essentially random (i.e., approximately $50 \%$ correct; Packard \& White, 1989, 1991). Thus, an 18-h delay allows for the assessment of potential memory-enhancing effects of the intrahippocampal glutamate injections. On the test day, the rats assigned in a rankorder method were removed from the maze after the first four food-rewarded choices and received a posttraining injection of either glutamate or saline into the hippocampus and a concurrent injection of either lidocaine or saline into the basolateral amygdala $(N=6-7$ rats/group).

\section{Results}

The mean number of trials to criterion (i.e., through the 5- and 15-min delay periods) for each group were as follows: hippocampus-saline/basolateral amygdala-saline, 16.17 trials, $1.61 S E M$; hippocampus-glutamate/basolateral amygdala-saline, 15.83 trials, $1.58 S E M$; hippocampusglutamate/basolateral amygdala-lidocaine, 16.71 trials, 1.34 SEM. A one-way ANOVA computed on the number of trials to criterion revealed no significant group effect $[F(2,160)=0.091$, n.s. $]$. The lack of group differences in the number of trials to criterion indicates that any effects produced by the posttraining treatments on the test day were not due to differential rates of task acquisition among groups.

The effects of concurrent posttraining intrahippocampal and intra-amygdala treatments on memory in the win-shift radial maze task are shown in Figure 4. A oneway ANOVA computed on the number of errors made on the retention test revealed a significant group effect $[F(2,16)=6.78, p<.01]$. Scheffe's post hoc tests revealed that the rats given concurrent intrahippocampal glutamate injections and intra-amygdala saline injections made significantly fewer errors than did rats receiving concurrent intrahippocampal and intra-amygdala saline injections $(F=3.73, p<.05)$. These findings indicate a memoryenhancing effect of intrahippocampal glutamate injections. In contrast, there was no significant difference in the number of retention test errors of the rats receiving concurrent intrahippocampal glutamate and intra-amygdala lidocaine injections and of the rats given concurrent intrahippocampal and intra-amygdala saline injections $(F=$ 0.24 , n.s.). This finding indicates that intra-amygdala lidocaine injections block the memory-enhancing effects of intrahippocampal injections of glutamate.

\section{Discussion}

Posttraining intrahippocampal injections of glutamate enhanced memory in the win-shift radial maze task, and this effect was blocked by concurrent posttraining administration of the local anesthetic lidocaine into the basolateral amygdala. The findings suggest that a func- 

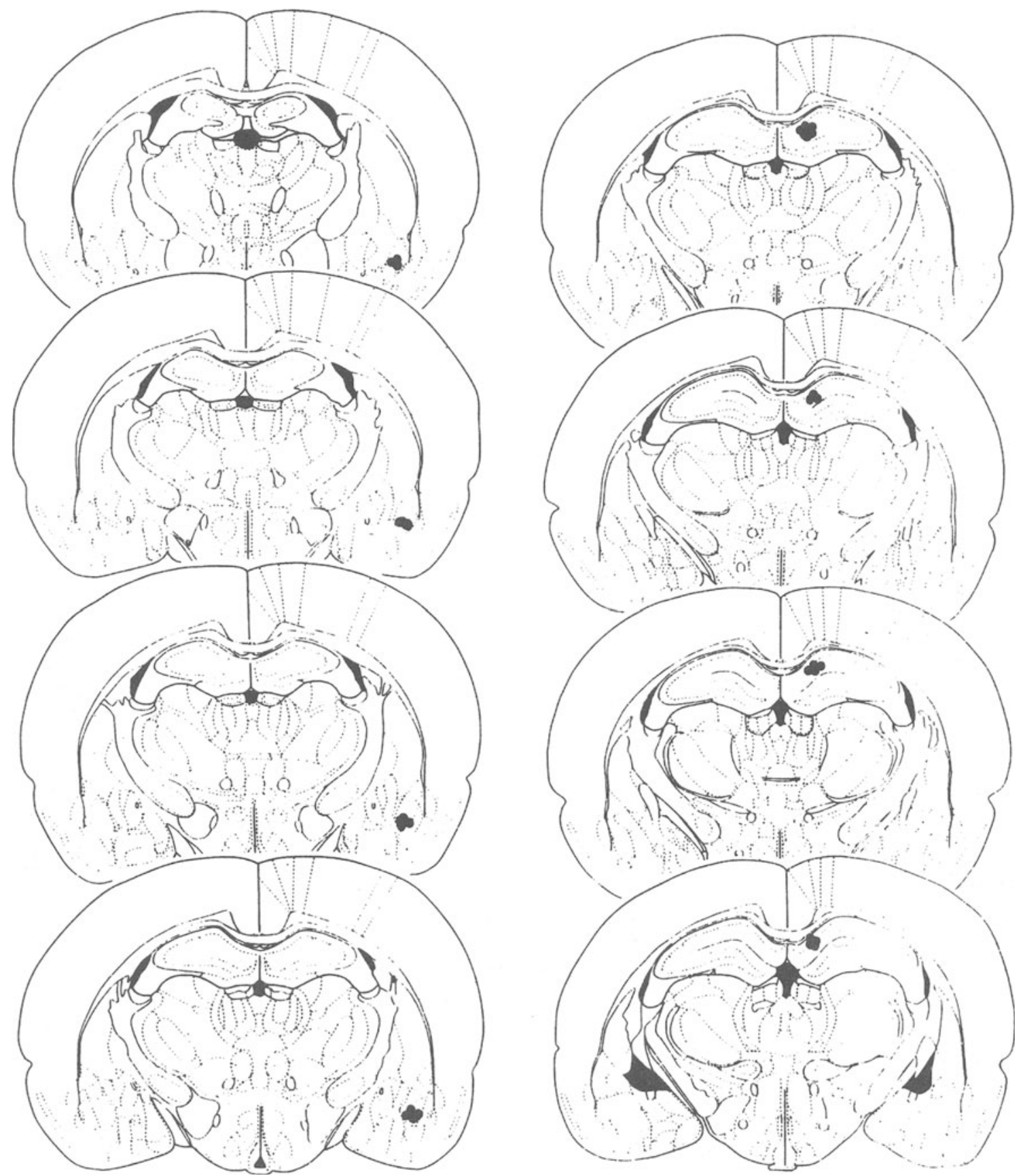

Figure 3. Injection needle tip locations (with overlap) for the combined unilateral (left-side) basolateral amygdala placements (left) and the dorsal hippocampal placements (right). Basolateral amygdala: top, -1.80 mm; upper middle, $-2.12 \mathrm{~mm}$; lower middle, $-2.30 \mathrm{~mm}$; bottom, $-2.56 \mathrm{~mm}$ from bregma. Dorsal hippocampus: top, $-2.80 \mathrm{~mm}$; upper middle, $-3.14 \mathrm{~mm}$; lower middle, $-\mathbf{3 . 3 0} \mathrm{mm}$; bottom, $-\mathbf{3 . 6 0} \mathbf{~ m m}$ from bregma (atlas of Paxinos \& Watson, 1997).

tional basolateral amygdala is a necessary cofactor in the memory-enhancing effect of posttraining intrahippocampal injection of glutamate.

The cofactor role of the amygdala in the memoryenhancing effects of intrahippocampal injection of glutamate is exerted despite the fact that posttraining infusions of lidocaine into the basolateral amygdala do not impair memory in the win-shift radial maze task (Experiment 1). This pattern of results is similar to that observed following lesions of the stria terminalis (a major afferent/ efferent pathway of the amygdala); stria lesions block the memory modulatory effects of numerous posttraining 


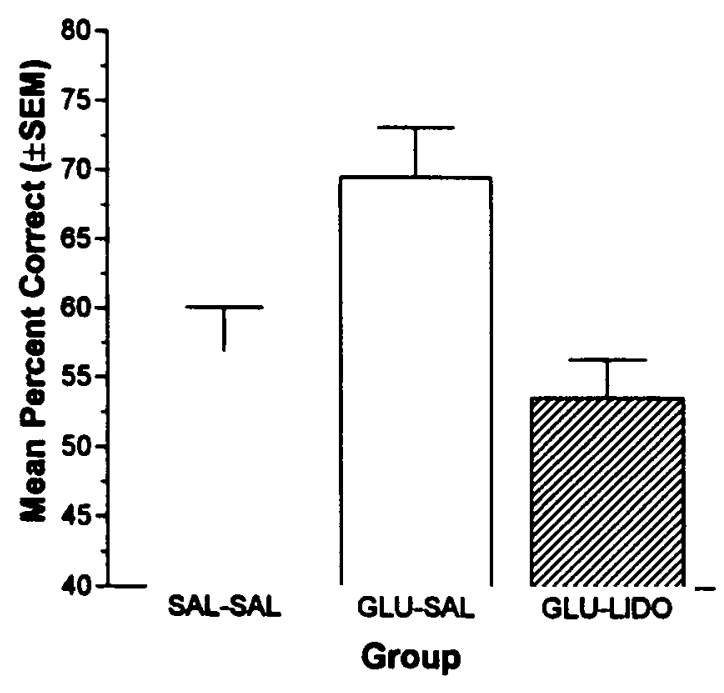

Figure 4. Effects of posttraining intrahippocampal injections of glutamate and concurrent intrabasolateral amygdala injections of lidocaine on memory in a win-shift radial maze task. SAL-SAL, saline-hippocampus/saline-basolateral amygdala; GLU-SAL, glutamate-hippocampus/saline-basolateral amygdala; GLU-LIDO, glutamate-hippocampus/lidocaine-basolateral amygdala; $S E M$, standard error of the mean.

drug treatments, without affecting task acquisition or retention in vehicle-injected rats (for a review, see Packard et al., 1995). Thus, one principle of the memory modulatory role of the basolateral amygdala (at least for hippocampal-dependent tasks) is that this function is apparently not necessary for normal memory acquisition or expression but is critical for the establishment of supranormal memories. It should be noted, however, that extensive evidence does support a role for specific amygdala nuclei in the acquisition and expression of memory in various fear conditioning (for reviews, see Davis, 1992; LeDoux, 1992) and stimulus-reward learning tasks in rats (see, e.g., Everitt, Cador, \& Robbins, 1989; Everitt, Morris, O'Brien, \& Robbins, 1991; Hiroi \& White, 1991; Kentridge, Shaw, \& Aggleton, 1991; Kesner, 1992; McDonald \& White, 1993; Peinado-Manzano, 1989; for a discussion of possible differences in the memory modulatory and storage roles of the amygdala, see Packard \& Teather, 1998).

In addition to the present study, a memory-enhancing effect of posttraining intrahippocampal glutamate injections has also been observed following inhibitory avoidance training (Flood, Baker, \& Davis, 1990; Izquierdo et al., 1992) and training in a hidden platform water maze task (Packard \& Teather, 1999). Although the mechanism by which intrahippocampal administration of glutamate enhances memory is unknown, one possibility is that the injections influence memory via an action on hippocampal synaptic plasticity. Consistent with this suggestion, activation of glutamatergic receptors in the hippocampus is an integral component of the induction of long-term potentiation, a putative physiological mechanism underlying memory (for a review, see Bliss \& Collinridge, 1993).

Further research is necessary in order to determine the mechanism by which amygdala efferent projections interact with glutamatergic transmission in the hippocampus to enhance memory. In addition to functional connections with the hippocampus (e.g., the dentate gyrus; Cahill \& McGaugh, 1993; Ikegaya et al., 1994), basolateral and lateral amygdala nuclei project directly to cortical regions (e.g., the entorhinal cortex) that provide glutamatergic input to the hippocampus (Finch et al., 1986; Krettek \& Price, 1977, 1978). Thus, amygdaloid influences on hippocampal memory processes may involve an ultimate action on synaptic plasticity in the dentate gyrus (lkegaya et al., 1994, 1995, 1996) initiated via modulation of entorhinal cortical neurons projecting to the hippocampus (Petrovich et al., 1997; Thomas, Assat, \& Iversen, 1984).

Finally, findings of functional dissociation experiments suggest that the hippocampal system and the caudate-putamen are parts of independent memory systems that differ in terms of the type of memory they mediate (Kesner, Bolland, \& Dakis, 1993; McDonald \& White, 1993; Packard, Hirsh, \& White, 1989; Packard \& McGaugh, 1992, 1996). Recent evidence suggests that, in addition to modulating the cognitive (Hirsh, 1974; Mishkin \& Petri, 1984) memory processes mediated by the hippocampus, the basolateral amygdala also exerts a modulatory influence on the $S-R$ habit (Mishkin \& Petri, 1984; Packard et al., 1989; Packard \& McGaugh, 1992, 1996) memory processes mediated by the caudate-putamen. For example, posttraining intra-amygdala injections of amphetamine enhance memory in a caudate-dependent visible platform water maze task, and this effect is blocked by concurrent intracaudate injection of lidocaine (Packard et al., 1994; Packard \& Teather, 1998). Moreover, lesions of the stria terminalis block the memory-enhancing effects of posttraining intracaudate injection of the cholinergic agonist oxotremorine (Packard, Introini-Collison, \& McGaugh, 1996). Thus, the functional integrity of amygdala efferent projections appears to be a necessary cofactor for the memory-enhancing effects of both hippocampal and caudate-putamen drug treatments, suggesting that the amygdala exerts a general modulatory influence on multiple forms of memory.

\section{REFERENCES}

Beatty, W. W., \& Shavalia, D. A. (1980). Spatial memory in rats: Time course of working memory and effects of anesthetics. Behavioral \& Neural Biology, 28, 454-462.

Becker, J. T., Walker, J. A., \& Olton, D. S. (1980). Neuroanatomical basis of spatial memory. Brain Research, 200, 307-320.

Bliss, T. V. P., \& CollinRidge, G. L. (1993). A synaptic model of memory: Long-term potentiation in the hippocampus. Nature, 361, 31-39.

Cahill, L., \& MCGaugh, J. L. (1993). The functional anatomy of amygdala efferent pathways. Society for Neuroscience Abstracts, 19 , 1226. 
Davis, M. (1992). The role of the amygdala in conditioned fear. In J. P. Aggleton (Ed.), The amygdala: Neurobiological aspects of emotion, memory, and mental dysfunction (pp. 255-306). New York: WileyLiss.

EveritT, B. J., Cador, M., \& RobBins, T. W. (1989). Interactions between the amygdala and ventral striatum in stimulus-reward associations: Studies using a second-order schedule of sexual reinforcement. Neuroscience, 30, 63-75.

EveritT, B. J., Morris, K. A., O'Brien, A., \& Robbins, T. W. (1991). The basolateral amygdala-ventral striatal system and conditioned place preference: Further evidence of limbic-striatal interactions underlying reward-related processes. Neuroscience, 42, 1-18.

Finch, D. M., Wong, E. E., Derian, E. L., Chen, X. H., NowlinFinch, N. L., \& BRothers, E. (1986). Neurophysiology of limbic system pathways in the rat: Projections from the amygdala to the entorhinal cortex. Brain Research, 370, 273-284.

FLOOD, J. F., BAKER, M. L., \& DAVIS, J. L. (1990). Modulation of memory processing by glutamic acid receptor agonists and antagonists Brain Research, 521, 197-202.

HiroI, N., \& WhiTe, N. M. (1991). The lateral nucleus of the amygdala mediates expression of the amphetamine conditioned place preference. Journal of Neuroscience, 11, 2107-2116.

HIRSH, R. (1974). The hippocampus and contextual retrieval from memory: A theory. Behavioral Biology, 12, 421-442.

IKEGAYA, Y., SAITo, H., \& ABE, K. (1994). Attenuated hippocampal long-term potentiation in basolateral amygdala lesioned rats. Brain Research, 656, 157-164.

Ikegaya, Y., Saito, H., \& ABE, K. (1995). Requirement of basolateral amygdala neuron activity for the induction of long-term potentiation in the dentate gyrus in vivo. Brain Research, 671, 351-354.

IKeGaya, Y., SAITo, H., \& ABE, K. (1996). Dentate gyrus field potentials evoked by stimulation of the basolateral amygdaloid nucleus in anesthetized rats. Brain Research, 718, 53-60.

Introini-Collison, I. B., Arai, Y., \& MCGaugh, J. L. (1989). Stria terminalis lesions attenuate the effects of posttraining oxotremorine and atropine on retention. Psychobiology, 17, 397-401.

Introini-Collison, I. B., Mivasaki, B., \& MCGaugh, J. L. (1991). Involvement of the amygdala in the memory-enhancing effects of clenbuterol. Psychopharmacology, 104, 541-544.

izquierdo, I., da Chuna, C., Rosat, R., Jerusalinsky, D., Ferreira, M. C. B., \& MEDiNA, J. (1992). Neurotransmitter receptors involved in posttraining memory processing by the amygdala, medial septum, and hippocampus of the rat. Behavioral \& Neural Biology, 58, 16-26.

Kentridge, R. W., Shaw, C., \& AGgleton, J. P. (1991). Amygdaloid lesions and stimulus-reward associations in the rat. Behavioural Brain Research, 42, 57-66.

KESNER, R. P. (1992). Learning and memory in rats with an emphasis on the role of the amygdala. In J. P. Aggleton (Ed.), The amygdala: Neurobiological aspects of emotion, memory, and mental dysfunction (pp. 370-400). New York: Wiley-Liss.

KeSner, R. P., Bolland, B. L., \& Dakis, M. (1993). Memory for spatial locations, motor responses, and objects: Triple dissociation among the hippocampus, caudate nucleus, and extrastriate visual cortex. Experimental Brain Research, 93, 462-470.

KREtTeK, J. E., \& PriCE, J. L. (1977). Projections from the amygdaloid complex and adjacent olfactory structures to the entorhinal cortex and subiculum in the rat and cat. Journal of Comparative Neurology, 172, 723-752.

Krettek, J. E., \& Price, J. L. (1978). Amygdaloid projections to subcortical structures within the basal forebrain and brainstem in the rat and cat. Journal of Comparative Neurology, 178, 225-254.

LeDoux, J. E. (1992). Emotion and the amygdala. In J. P. Aggleton (Ed.), The amygdala: Neurobiological aspects of emotion, memory, and mental dysfunction (pp. 323-338). New York: Wiley-Liss.

LiANG, K. C., \& MCGAUGH, J. L. (1983). Lesions of the stria terminalis attenuate the enhancing effect of posttraining epinephrine on retention of an inhibitory avoidance response. Behavioural Brain Research, 9, 49-58.

Maki, W. S., Beatty, W. W., Hoffman, N., Bierly, R. A., \& Clouse,
B. A. (1984). Spatial memory over long retention intervals: Nonmemorial factors are not necessary for accurate performance in the radial maze by rats. Behavioral \& Neural Biology, 41, 1-6.

McDonald, R. J., \& White, N. M. (1993). A triple dissociation of memory systems: Hippocampus, amygdala, and dorsal striatum. Behavioral Neuroscience, 107, 3-22.

McGaugh, J. L., Cahill, L., \& RoozendaAl, B. (1996). Involvement of the amygdala in memory storage: Interaction with other brain systems. Proceedings of the National Academy of Sciences, 93, 1350813514.

MCGaugh, J. L., InTroini-Collison, I. B., Juler, R. G., \& IzQUIERDO, I. (1986). Stria terminalis lesions attenuate the effects of post-training naloxone and beta-endorphin on retention. Behavioral Neuroscience, 100, 839-844.

McIntyre, C. K., Ragozzino, M. E., \& Gold, P. E. (1998). Intraamygdala infusions of scopolamine impair performance on a conditioned place preference task but not a spatial radial maze task. Behavioural Brain Research, 95, 219-226.

Mishinin, M., \& PETRI, H. L. (1984). Memories and habits: Some implications for the analysis of learning and retention. In L. R. Squire \& N. Butters (Eds.), Neuropsychology of memory (pp. 287-296). New York: Guilford.

Ottersen, O. P., Osen, K. K., \& LaAKe, J. H. (1995). Amino acid transmitters. In G. Paxinos (Ed.), The rat nervous system (pp. 1017-1040). New York: Academic Press.

Packard, M. G., Cahill, L., \& McGaugh, J. L. (1994). Amygdala modulation of hippocampal-dependent and caudate nucleus-dependent memory processes. Proceedings of the National Academy of Sciences, 91, 8477-8481.

Packard, M. G., HirSh, R., \& White, N. M. (1989). Differential effects of fornix and caudate nucleus lesions on two radial maze tasks: Evidence for multiple memory systems. Journal of Neuroscience, 9 , 1465-1472.

Packard, M. G., Introini-Collison, I. B., \& McGaugh, J. L. (1996). Stria terminalis lesions attenuate memory enhancement produced by intracaudate nucleus injections of oxotremorine. Neurobiology of Learning \& Memory, 65, 278-282.

Packard, M. G., \& McGaugh, J. L. (1992). Double dissociation of fornix and caudate nucleus lesions on acquisition of two water maze tasks: Further evidence for multiple memory systems. Behavioral Neuroscience, 106, 439-446.

Packard, M. G., \& McGaugh, J. L. (1996). Inactivation of the hippocampus or caudate nucleus with lidocaine differentially affects expression of place and response learning. Neurobiology of Learning \& Memory, 65, 65-72.

Packard, M. G., \& Teather, L. A. (1998). Amygdala modulation of multiple memory systems: Hippocampus and caudate-putamen. Neurobiology of Learning \& Memory, 69, 163-203.

Packard, M. G., \& Teather, L. A. (1999). Dissociation of multiple memory systems by posttraining intracerebral injections of glutamate. Psychobiology, 27, 40-50.

PaCkard, M. G., \& White, N. M. (1989). Memory facilitation produced by dopamine agonists: Role of receptor subtype and mnemonic requirements. Pharmacology. Biochemistry \& Behavior, 33, 511518.

PaCKard, M. G., \& White, N. M. (1991). Dissociation of hippocampus and caudate nucleus memory systems by posttraining intracerebral injection of dopamine agonists. Behavioral Neuroscience, 105, 295306.

Packard, M. G., Williams, C. L., Cahill, L., \& McGaugh, J. L. (1995). The anatomy of a memory modulatory system: From periphery to brain. In N. E. Spear, L. P. Spear, \& M. L. Woodruff (Eds.), Neurobehavioral plasticity: Learning, development, and response to brain insults (pp. 149-183). Hillsdale, NJ: Erlbaum.

Parent, M. B., \& MCGaugh, J. L. (1994). Posttraining infusion of lidocaine into the amygdala basolateral complex impairs retention of inhibitory avoidance training. Brain Research, 661, 97-103.

Paxinos, G., \& WATSON, C. (1997). The rat brain in stereotaxic coordinates (3rd ed.). San Diego: Academic Press. 
Peinado-Manazo, M. A. (1989). Intervention of the lateral and central amygdala on the association of visual stimuli with different magnitudes of reinforcement. Behavioural Brain Research, 32, 289-296.

Petrovich, G. D., Canteras, N. S., \& Swanson, L. W. (1997). Organization of amygdalar projections to the hippocampal formation: A PHAL study in the rat. Society for Neuroscience Abstracts, 23, 2101.

RaGGozzino, M. E., \& Gold, P. E. (1994). Task-dependent effects of intra-amygdala morphine injections, attenuation by intra-amygdala glucose injections. Journal of Neuroscience, 14, 7478-7485.

RoOzendaAL, B., \& McGaugh, J. L. (1997). Basolateral amygdala lesions block the memory-enhancing effect of glucocorticoid administration in the dorsal hippocampus of rats. European Journal of Neuroscience, 9, 76-83.
SQuire, L. R., Knowlton, B. J., \& Musen, G. (1993). The structure and organization of memory. Annual Review of Psychology, 44, 453495.

Sutherland, R. J., \& McDonald, R. J. (1990). Hippocampus, amygdala, and memory deficits in rats. Behavioural Brain Research, 37, 57-79.

Thomas, S. R., Assaf, S. Y., \& Iversen, S. D. (1984). Amygdaloid complex modulates neurotransmission from the entorhinal cortex to the dentate gyrus of the rat. Brain Research, 307, 363-365.

(Manuscript received October 7, 1998; revision accepted for publication December 21, 1998.) 